\title{
Correction: The Effect of a Health Game Prompt on Self-efficacy: Online Between-Subjects Experimental Survey
}

Priscilla Haring, MSc

\section{Corresponding Author:}

Priscilla Haring, MSc

Witte de withstraat $20 \mathrm{hs}$

Amsterdam, 1057XW

Netherlands

Phone: 31624813683

Email: priscillaharing@hotmail.com

\section{Related Article:}

Correction of: https://games.jmir.org/2021/1/e20209/

(JMIR Serious Games 2021;9(1):e28894) doi: 10.2196/28894

In "The Effect of a Health Game Prompt on Self-efficacy: Online Between-Subjects Experimental Survey" (JMIR Serious Games 2021;9(1):e20209) the author noted one error.

In the originally published paper, the Corresponding Author address for author Priscilla Haring inadvertently listed the incorrect country as well as the incorrect country code in the author's phone number. The originally published Corresponding Author address was listed as follows:

Priscilla Haring, MSc

Witte de withstraat 20hs

Amsterdam, 1057XW

India

Phone: 91624813683

Email: priscillaharing@hotmail.com
This has been corrected to:

Priscilla Haring, MSC

Witte de withstraat 20hs

Amsterdam, 1057XW

Netherlands

Phone: 31624813683

Email: priscillaharing@hotmail.com

The correction will appear in the online version of the paper on the JMIR Publications website on March 22, 2021, together with the publication of this correction notice. Because this was made after submission to PubMed, PubMed Central, and other full-text repositories, the corrected article has also been resubmitted to those repositories.

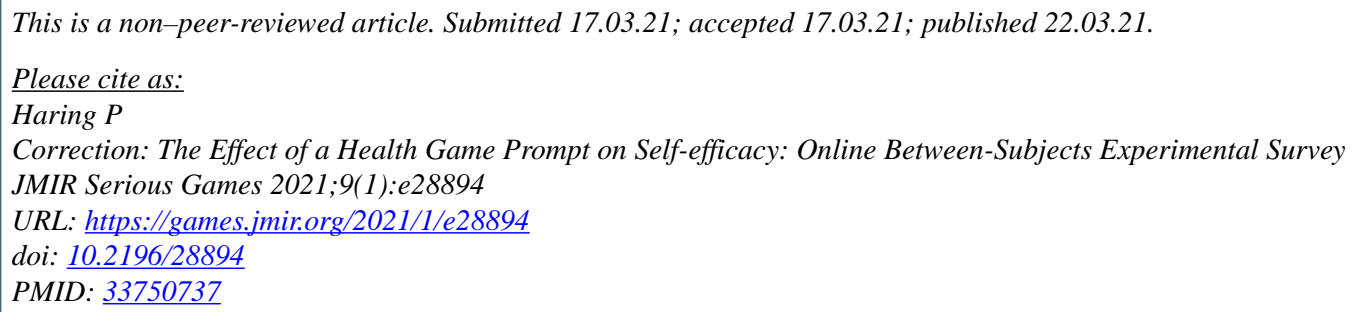

CPriscilla Haring. Originally published in JMIR Serious Games (http://games.jmir.org), 22.03.2021. This is an open-access article distributed under the terms of the Creative Commons Attribution License (https://creativecommons.org/licenses/by/4.0/), which permits unrestricted use, distribution, and reproduction in any medium, provided the original work, first published in JMIR Serious Games, is properly cited. The complete bibliographic information, a link to the original publication on http://games.jmir.org, as well as this copyright and license information must be included. 